\title{
A novel system for predicting the toxicity of irinotecan based on statistical pattern recognition with $U G T 1 A$ genotypes
}

\author{
RYOUICHI TSUNEDOMI $^{1}$, SHOICHI HAZAMA ${ }^{1}$, YUSUKE FUJITA ${ }^{2}$, NAOKO OKAYAMA ${ }^{3}$, \\ SHINSUKE KANEKIYO ${ }^{1}$, YUKA INOUE ${ }^{1}$, SHIGEFUMI YOSHINO ${ }^{1}$, TAKAHIRO YAMASAKI ${ }^{3}$, \\ YUTAKA SUEHIRO $^{3}$, KOJI OBA ${ }^{4}$, HIDEYUKI MISHIMA ${ }^{5}$, JUNICHI SAKAMOTO ${ }^{6}$, \\ YOSHIHIKO HAMAMOTO $^{2}$ and MASAAKI OKA ${ }^{1}$
}

\begin{abstract}
${ }^{1}$ Department of Digestive Surgery and Surgical Oncology, Yamaguchi University Graduate School of Medicine, Yamaguchi 755-8505; ${ }^{2}$ Department of Computer Science and Systems Engineering, Faculty of Engineering, Yamaguchi University, Yamaguchi 755-8611; ${ }^{3}$ Department of Clinical Laboratory, Yamaguchi University Hospital, Yamaguchi 755-8505; ${ }^{4}$ Translational Research and Clinical Trial Center, Hokkaido University Hospital, Sapporo 060-8638;

${ }^{5}$ Unit of Cancer Center, Aichi Medical University, Nagakute 480-1195; ${ }^{6}$ Tokai Central Hospital, Aichi 504-8601, Japan
\end{abstract}

Received April 24, 2014; Accepted June 10, 2014

DOI: $10.3892 /$ ijo.2014.2556

\begin{abstract}
To predict precisely severe toxicity of irinotecan, we evaluated the association of UGTIA variants, haplotypes and the combination of UGTIA genotypes to severe toxicity of irinotecan. UGT1Al*6 $(211 G>A), U G T 1 A 1 * 28\left(T A_{6}>T A_{7}\right)$, UGT1A1*60 $(-3279 T>G)$, UGT1A7 $(387 T>G)$, UGTIA7 $(622 T>C)$, and $U G T 1 A 9 * 1 b\left(-118 T_{9}>T_{10}\right.$, also named $\left.* 22\right)$ were genotyped in 123 patients with metastatic colorectal cancer who had received irinotecan-based chemotherapy. Among the 123 patients, 73 were enrolled in either of two phase II studies of the FOLFIRI (leucovorin, 5-fluorouracil and irinotecan) regimen; these patients constituted the training population, which was used to construct the predicting system. The other 50 patients constituted the validation population; these 50 patients either had participated in a phase II study of irinotecan/5'-deoxy-5-fluorouridine or were among consecutive patients who received FOLFIRI therapy. This prediction system used sequential forward floating selection based on statistical pattern recognition using UGT1A genotypes, gender and age. Several UGT1A genotypes [UGT1A1*6, UGT1A7 $(387 T>G), U G T 1 A 7(622 T>C)$ and $U G T 1 A 9 * 1 b]$ were associated with the irinotecan toxicity. Among the haplotypes, haplotype-I (UGT1A1: -3279T, TA 6 , 211G; UGT1A7: 387T, 622T; UGT1A9: $\mathrm{T}_{10}$ ) and haplotype-II (UGTIAl: -3279T, TA, 211A; UGT1A7: 387G, 622C; UGT1A9: $\mathrm{T}_{9}$ ) were also associ-
\end{abstract}

Correspondence to: Professor Masaaki Oka, Department of Digestive Surgery and Surgical Oncology, Yamaguchi University Graduate School of Medicine, 1-1-1 Minami-Kogushi, Ube, Yamaguchi 755-8505, Japan

E-mail: 2geka-1@yamaguchi-u.ac.jp

Key words: irinotecan, polymorphisms, prediction, toxicity, uridin diphosphate-glucuronosyltransferase $1 \mathrm{~A}$ ated with irinotecan toxicity. Furthermore, our new system for predicting the risk of irinotecan toxicity was $83.9 \%$ accurate with the training population and $72.1 \%$ accurate with the validation population. Our novel prediction system using statistical pattern recognition depend on genotypes in UGT1A, age and gender; moreover, it showed high predictive performance even though the treatment regimens differed among the training and validation patients.

\section{Introduction}

Concurrent irinotecan and fluorinated-pyrimidine is a common first-line therapy for metastatic colorectal cancer (mCRC) (1-6). Although prolonged survival is associated with regimens involving irinotecan, severe neutropenia occurs in $20-35 \%$ of mCRC cases treated with irinotecan regimens. Carboxylesterases catabolized irinotecan to 7-ethyl-10-hydroxycamptothecin (SN-38), which is a potent topoisomerase I inhibitor $(7,8)$. $\mathrm{SN}-38$ is then further catabolized by hepatic uridin diphosphate-glucuronosyltransferase (UGT) 1 A enzymes to an inactive SN-38 glucuronide (SN-38G) (9). Many mCRC patients with a genetic variant $(U G T 1 A 1 * 28)$ experience severe irinotecan toxicity; $U G T 1 A 1 * 28$ is a variation in the number (seven vs. six) of TA repeats in the promoter region of $U G T 1 A 1(10,11)$. Interestingly, the toxicity and tumor response of concurrent leucovorin, 5-fluorouracil, and irinotecan (FOLFIRI) reportedly also correlate with UGTIA variants (UGT1A1, UGT1A7 and UGT1A9) and haplotypes including these variants (12-18). There are differences between Caucasian and Asian populations in frequencies of UGT1A variants, and $U G T 1 A I^{*} 6$ reportedly associates strongly with severe neutropenia especially among Asian patients $(12,17)$.

To predict the risk of irinotecan toxicity for individual patients, it is important that determining the relative contributions of UGTIA variants other than UGTIAI*28 and $U G T 1 A 1 * 6$ is important to the development of any system designed to predict irinotecan toxicity for individual patients 
because patients without $U G T 1 A 1 * 28$ or $* 6$ do experience severe irinotecan toxicity. Several studies have examined associations between irinotecan toxicity and UGT1A haplotypes in addition to each genotype of UGT1A (17-19). However, determining the haplotype or diplotype for each patient is difficult; moreover, most haplotypes and diplotypes are too rare to constitute a group large enough for meaningful statistical analysis. Moreover, gender and age of patients each reportedly have an impact on irinotecan toxicity (20-22). Hence, these factors should be also taken into consideration when developing a system designed to predict irinotecan toxicity.

The aim of this study was to evaluate whether the combinations of UGT1A genotypes, but not haplotypes, together with patient characteristics might be useful in predicting the risk to patients with mCRC treated of irinotecan-containing regimens. Here, we investigated the genotypes of 123 patients at six loci: UGT1A1*6 (211G $>\mathrm{A}, \mathrm{rs} 4148323), U G T 1 A 1 * 28$ $\left(\mathrm{TA}_{6}>\mathrm{TA}_{7}, \mathrm{rs} 8175347\right), U G T 1 A 1 * 60(-3279 \mathrm{~T}>\mathrm{G}, \mathrm{rs} 4124874)$, UGT1A7 (387T $>\mathrm{G}$, rs17868323), UGT1A7 $(622 \mathrm{~T}>\mathrm{C}$, rs11692021), and $U G T 1 A 9 * 1 b\left(-118 \mathrm{~T}_{9}>\mathrm{T}_{10}\right.$, rs35426722, also called $U G T 1 A 9 * 22)$ (23). Next, we evaluated the contribution of each UGT1A genotype, haplotype, and diplotype to the risk of irinotecan toxicity. Furthermore, we developed a new system for predicting the risk that a patient will experience irinotecan toxicity; this system uses sequential forward floating selection (SFFS) algorithm based on statistical pattern recognition to select the combinations of UGT1A genotypes, gender and age. SFFS is a sequential search method characterized by a dynamically changing number of features included or eliminated at each step of an individual analysis (24). This is the first study conducted to assess the role of the combination of genotypes at six polymorphic sites in $U G T 1 A$ and clinical features constructed by SFFS on the risk of irinotecan toxicity.

\section{Materials and methods}

Patients. In this study, $123 \mathrm{mCRC}$ patients were examined for association between UGT1A genotypes and irinotecan toxicity (Table I). This study was performed as an ancillary investigation; data collected from three prospective studies [FLIGHT1 (5), FLIGHT2 (5) and FRUTIRI (6)] and from consecutive patients who received FOLFIRI at the Department of Digestive Surgery and Surgical Oncology, Yamaguchi University Graduate School of Medicine, Japan. Each participant received irinotecan at the dose of $150 \mathrm{mg} / \mathrm{m}^{2}$, which has been approved in Japan.

FLIGHT1 (UMIN000002388) and FLIGHT2 (UMIN000002476) were phase II studies of first line and second line chemotherapy, respectively, for mCRC. Study designs and key eligibility and exclusion criteria have been described in detail $(5,25,26)$. Briefly, each regimen consisted of irinotecan on day $1+400 \mathrm{mg} / \mathrm{m}^{2}$ fluorouracil bolus followed by $2,400 \mathrm{mg} / \mathrm{m}^{2}$ fluorouracil continuous infusion during $46 \mathrm{~h}+200 \mathrm{mg} / \mathrm{m}^{2}$ leucovorin on day 1 every 2 weeks. Of all patients from the FLIGHT1 and FLIGHT2 studies, 38 and 35, respectively, participated in this ancillary investigation and use; these 73 patients constituted the training population. FLIGHT1 or FLIGHT2 patients homozygous for UGTIAI*28 were excluded from the training population because these patients received a lower starting dose of irinotecan $\left(100 \mathrm{mg} / \mathrm{m}^{2}\right)(5)$.
The validation population comprised 50 patients from two different study groups: 22 patients who participated in FRUTIRI (UMIN000005011), a phase II study of a combination therapy comprised irinotecan and 5'-deoxy-5-fluorouridine (5'-DFUR) (6) and 28 consecutive patients who underwent second-line FOLFILI treatment between October, 2008 and July, 2012 in the Department of Digestive Surgery and Surgical Oncology, Yamaguchi University Graduate School of Medicine, Japan. Detail treatment regimen tested in FRUTIRI was described previously (6). Briefly, irinotecan was administered every two weeks, and $400 \mathrm{mg}$ 5'-DFUR was administered every week orally twice a day on five consecutive days that were followed by a weekly 2-day washout. The 28 consecutive patients undergoing FOLFIRI treatment were following the protocol used in FLIGHT2 (26). In a validation population, patients with $U G T 1 A 1 * 28$ homozygous were not found in the FRUTIRI study $(\mathrm{n}=28)$. Additionally, patients heterozygous for $U G T 1 A 1 * 28(\mathrm{n}=6)$ were excluded from the FRUTIRI study because these patients received lower starting dose of irinotecan $70 \mathrm{mg} / \mathrm{m}^{2}$. Among the 28 consecutive patients who received second-line FOLFILI therapy, homozygous for $U G T 1 A 1 * 6$ or $* 28$ and those compound heterozygous for $U G T 1 A 1 * 6$ and $U G T 1 A 1 * 28$ been excluded from this ancillary study. The training $(n=73)$ and validation $(n=50)$ populations did not differ significantly with regard to the distribution of any clinical feature or genotype that is listed in Table I except for the distributions of the UGT1A7 $(387 T>G)$ and $U G T 1 A 9 * 1 b$ alleles (data not shown).

In this study, we defined patients who exhibited hematologic toxicity greater than grade 3 during the entire course of therapy as experiencing irinotecan toxicity. The study protocols were approved by the Institutional Review Board at Yamaguchi University Graduate School of Medicine, and were carried out in accordance with the Helsinki declaration on experimentation on human subjects. Each patient gave written, informed consent for their participation in this study.

Genotyping of UGT1A and haplotype construction. A conventional sodium iodide (NaI) method was used to extract genomic DNA from peripheral blood samples (27). The number of TA repeats in the UGT1A1 promoter region was determined by the fragment size analysis followed by direct sequencing as described previously (4). The TaqMan technique with a hydrolysis probe was used to determine the $U G T 1 A 1 * 6$ genotype as described previously (28); similarly, hydrolysis probes were used to determine the genotypes at $U G T 1 A 1 * 60$; a direct sequencing method was also used to determine the genotypes at UGT1A7 (387T $>\mathrm{G}$ and $622 \mathrm{~T}>\mathrm{C})$ and $U G T 1 A 9 * 1 b$.

Each nucleotide variant was evaluated to determine whether it was in Hardy-Weinberg equilibrium; Haploview 4.2 software was used to perform the linkage disequilibrium (LD) and case-control haplotype analyses (29). Lewontin's coefficient $\mathrm{D}^{\prime}$ and correlation coefficient $r^{2}$ were calculated as measures of LD.

Construction of toxicity prediction system by genotype combinations. To predict severe toxicities of irinotecan, the age, the gender and a comprehensive 6-site UGT1A genotype were determined for each of the 73 patients in the training population. SFFS, a method of statistical pattern recognition, was 
Table I. Characteristics of the patients.

\begin{tabular}{|c|c|c|c|c|c|c|}
\hline \multirow[b]{2}{*}{$\begin{array}{l}\text { Clinical features } \\
\text { and genotypes }\end{array}$} & \multirow[b]{2}{*}{$\begin{array}{c}\text { Total } \\
(\mathrm{n}=123)\end{array}$} & \multicolumn{4}{|c|}{ Sub-population (treatment regimen) } & \\
\hline & & $\begin{array}{l}{\text { FLIGHT } 1^{\mathrm{a}}}_{(\mathrm{n}=38)}\end{array}$ & $\begin{array}{l}\text { FLIGHT2 }^{\mathrm{a}} \\
(\mathrm{n}=35)\end{array}$ & $\begin{array}{l}\text { FRUTIRI }^{b} \\
\quad(\mathrm{n}=22)\end{array}$ & $\begin{array}{l}\text { 2nd-line FOLFILI }{ }^{\mathrm{c}} \\
\qquad(\mathrm{n}=28)\end{array}$ & \\
\hline \multicolumn{7}{|c|}{ Toxicity of irinotecan } \\
\hline No & 72 & 20 & 19 & 16 & 17 & $\mathrm{NS}^{\mathrm{d}}$ \\
\hline Yes & 51 & 18 & 16 & 6 & 11 & \\
\hline \multicolumn{7}{|l|}{ Gender } \\
\hline Male & 78 & 24 & 24 & 17 & 13 & $\mathrm{NS}^{\mathrm{d}}$ \\
\hline Female & 45 & 14 & 11 & 5 & 15 & \\
\hline \multicolumn{7}{|l|}{ Age } \\
\hline$\leq 60$ & 50 & 14 & 14 & 9 & 13 & $N S^{d}$ \\
\hline$>60$ & 73 & 24 & 21 & 13 & 15 & \\
\hline \multicolumn{7}{|l|}{$U G T 1 A 1 * 6$} \\
\hline$-/-$ & 84 & 25 & 23 & 15 & 21 & $\mathrm{NS}^{\mathrm{d}}$ \\
\hline$-/ * 6$ & 36 & 12 & 11 & 6 & 7 & \\
\hline$* 6 / * 6$ & 3 & 1 & 1 & 1 & $0^{c}$ & \\
\hline \multicolumn{7}{|l|}{$U G T 1 A 1 * 28$} \\
\hline$-/-$ & 103 & 32 & 27 & 22 & 22 & $\mathrm{NS}^{\mathrm{d}}$ \\
\hline$-/ * 28$ & 20 & 6 & 8 & $0^{\mathrm{b}}$ & 6 & \\
\hline$* 28 / * 28$ & 0 & $0^{\mathrm{a}}$ & $0^{\mathrm{a}}$ & $0^{\mathrm{b}}$ & $0^{\mathrm{c}}$ & \\
\hline \multicolumn{7}{|l|}{$U G T 1 A 1 * 60$} \\
\hline$-/-$ & 71 & 19 & 21 & 15 & 16 & $\mathrm{NS}^{\mathrm{d}}$ \\
\hline$-/ * 60$ & 46 & 17 & 12 & 6 & 11 & \\
\hline$* 60 / * 60$ & 6 & 2 & 2 & 1 & 1 & \\
\hline \multicolumn{7}{|l|}{ UGT1A7 } \\
\hline $387 \mathrm{~T} / \mathrm{T}$ & 41 & 13 & 12 & 8 & 8 & $\mathrm{NS}^{\mathrm{d}}$ \\
\hline $387 \mathrm{~T} / \mathrm{G}$ & 69 & 18 & 18 & 13 & 20 & \\
\hline $387 \mathrm{G} / \mathrm{G}$ & 13 & 7 & 5 & 1 & 0 & \\
\hline \multicolumn{7}{|l|}{ UGT1A7 } \\
\hline $387 \mathrm{~T} / \mathrm{T}$ & 70 & 21 & 19 & 14 & 16 & $\mathrm{NS}^{\mathrm{d}}$ \\
\hline $387 \mathrm{~T} / \mathrm{G}$ & 48 & 15 & 13 & 8 & 12 & \\
\hline $387 \mathrm{G} / \mathrm{G}$ & 5 & 2 & 3 & 0 & 0 & \\
\hline \multicolumn{7}{|l|}{$U G T 1 A 9 * 1 b$} \\
\hline$* 1 b / * 1 b$ & 43 & 14 & 12 & 9 & 8 & $\mathrm{NS}^{\mathrm{d}}$ \\
\hline$-/ * 1 b$ & 67 & 17 & 18 & 12 & 20 & \\
\hline$-/-$ & 13 & 7 & 5 & 1 & 0 & \\
\hline
\end{tabular}

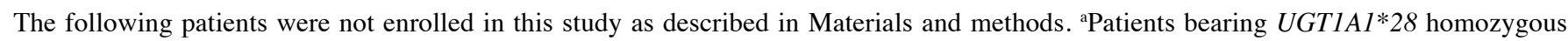
were excluded from the FLIGHT1 and FLIGHT2 studies. ${ }^{b}$ Homozygous and heterozygous of $U G T 1 A 1 * 28$ were not enrolled in the FRUTIRI study. 'Homozygous of $U G T 1 A 1 * 6$ and $* 28$ and compound heterozygous of $U G T 1 A 1 * 6$ and $* 28$ were not included in the consecutive patients received second-line FOLFILI therapy. ${ }^{\mathrm{d}} \mathrm{NS}$, not significant among 4 groups by Fisher's exact test.

then used to determine the optimal genotype combinations for predicting the risk of irinotecan toxicity. The statistical pattern recognition, SFFS, identified the genotype combinations with the 'maximum number of cases' and 'maximum prediction rate' to maximize overall diagnostic accuracy (24). Briefly, the algorithm of the SFFS used in this study was as follows: i) Suppose that at stage $k$ we have a set of $X_{1}, \ldots, X_{k}$ of sizes 1 to $k$, respectively. ii) Let the corresponding values of the feature selection criteria be $J_{l}$ to $J_{k}$, where $J_{i}=J\left(X_{i}\right)$, for the feature selection criterion $J($.). iii) Let the total set of features be $X$. Then at the $k$ th stage of the SFFS procedure follow these steps: Step 1, select the feature $x_{j}$ from $X-X_{k}$ that increases the value of $J$ to the greatest degree and add it to the current set: $X_{(k+1)}=X_{k}$ $+x_{j}$. Step 2, find the feature $x_{r}$ in the current set $X_{(k+1)}$ that reduces the value of $J$ the least; if this feature is the same as $x_{j}$ then set $J_{(k+1)}=J\left(X_{(k+1)}\right)$; increment $k$; go to step 1; otherwise 
Table II. Minor allele frequency and Hardy-Weinberg equilibrium in 123 patients.

\begin{tabular}{|c|c|c|c|c|}
\hline & \multicolumn{2}{|c|}{103 patients $^{\mathrm{a}}$} & \multicolumn{2}{|c|}{123 patients $^{\mathrm{b}}$} \\
\hline & MAF & HWp & MAF & HWp \\
\hline$U G T 1 A 1 * 6[211(\mathrm{G}>\mathrm{A})]$ & 0.18 & 1.00 & 0.17 & 1.00 \\
\hline$U G T 1 A I * 28\left[(\mathrm{TA})_{6}>(\mathrm{TA})_{7}\right]$ & 0.12 & 0.80 & 0.08 & 0.86 \\
\hline$U G T 1 A I * 60[-3279(\mathrm{~T}>\mathrm{G})]$ & 0.27 & 0.99 & 0.24 & 0.92 \\
\hline UGT1A7 [387 (T>G)] & 0.42 & 1.00 & 0.39 & 0.07 \\
\hline UGT1A7 [622 (T>C)] & 0.27 & 0.61 & 0.24 & 0.54 \\
\hline UGTIA9*1b $\left[-118\left(\mathrm{~T}_{9}>\mathrm{T}_{10}\right)\right]$ & 0.41 & 0.84 & 0.38 & 0.13 \\
\hline
\end{tabular}

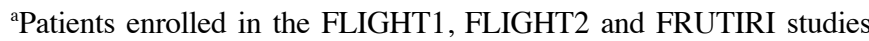
(patients received lower starting dose of irinotecan were not excluded). bPatients subjected to case-control study (patients received lower starting dose of irinotecan were excluded). MAF, minor allele frequency. HWp, p-value of Hardy-Weinberg equilibrium.

remove it from the set to from $X_{k}^{\prime}=X_{(k+1)}-x_{r}$. Step 3, continue removing features from the set $X_{k}^{\prime}$ to form reduced sets $X_{(k-1)}^{\prime}$ while $J\left(X_{(k-1)}^{\prime}\right)>J_{(k-1)} ; k=k-1$; until $k=2$; then continue with step 1 . The algorithm is initialized by setting $k=0$ and $X_{0}=\varnothing$.

Statistical analysis. Fisher's exact test was used to assess the relationship between toxicity and each UGTIA variant. The Cochran-Armitage trend test was used to examine the linearity of the relationship between UGTIA genotypes and irinotecan toxicity. SPSS Statics 17.0 software (IBM, Tokyo, Japan) and $\mathrm{R}$ version 2.13.0 software were used to perform the calculations (30). $\mathrm{p}<0.05$ was considered statistically significant.

\section{Results}

UGT1A allele and haplotype frequencies. The minor allele frequencies (MAF) of each UGTIA allele among the 103 patients without genetic bias; all patients regardless of the starting dose of irinotecan enrolled in FLIGHT1, FLIGHT2, and FRUTIRI studies, and 123 patients received a starting dose of $150 \mathrm{mg} / \mathrm{m}^{2}$ for case-control study participating in this study are listed in Table II. In this study, the MAFs of $U G T 1 A 1 * 28$ and $U G T 1 A 1 * 6$ were approximately 0.117 and 0.184 , respectively. The MAF for each other UGTIA SNP examined in this study was greater than 0.20 . Among all patients, the Hardy-Weinberg equilibrium p-value for each locus examined in this study was higher than 0.05. LD analysis with 103 patients showed that high LD $\left(r^{2}>0.9\right)$ was evident between UGTIA7 $(387 T>G)$ and UGT1A9*1b (Fig. 1). We found 12 UGTIA haplotypes (Hp-I to $H p$-XII) using 6 loci in 103 patients: $U G T 1 A 1 * 6, * 28, * 60, U G T 1 A 7(387 T>G)$, UGT1A7 $(622 T>C)$, and UGT1A9*1b (Table III). Three common haplotypes (Hp-I, Hp-II and Hp-III) accounted for $82.5 \%$ of all haplotypes identified in this study.

Associations between UGT1A genotypes/haplotypes and irinotecan toxicity. We examined associations between individual
A The Lewontin's coefficient D'

B The correlation coefficient $r^{2}$
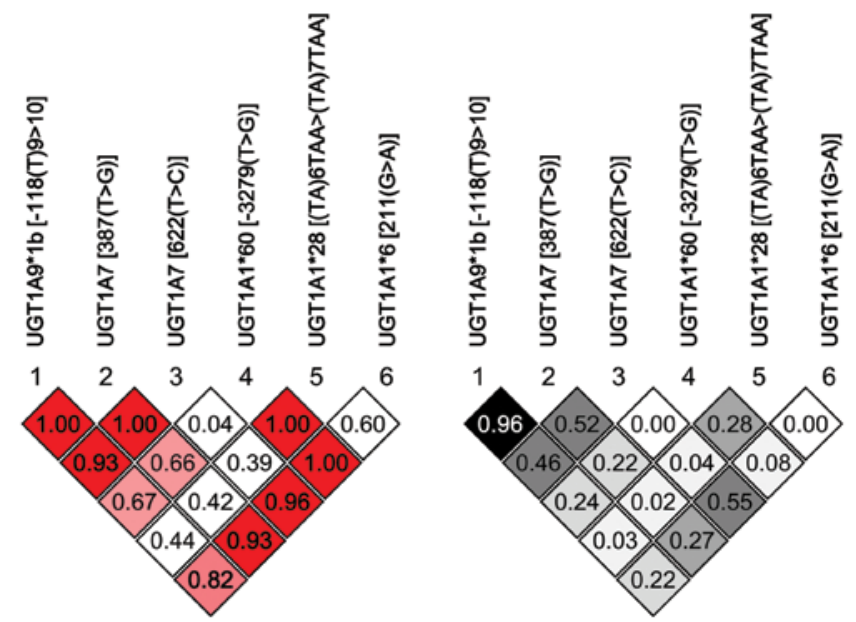

Figure 1. Pairwise linkage disequilibrium relationships between the UGT1A variants. (A) The Lewontin's coefficient $\mathrm{D}^{\prime}$ and (B) the correlation coefficient $r^{2}$ are represented as values and colors [in panel $\mathrm{A}, \log$ of the odds (LOD) $\geq 2$ shades of pink/red, $\mathrm{LOD}<2$ and $\mathrm{D}^{\prime}=1$ is blue, and LOD $<2$ and $\mathrm{D}^{\prime}<1$ is white. In panel $\mathrm{B}, r^{2}<0.01$ is white, $0.01 \leq r^{2}<0.95$ is shades of grey, and $r^{2} \geq 0.95$ is black] in each box.

UGTIA genotypes or haplotypes and severe irinotecan toxicity among 123 patients with mCRC who receive chemotherapy that included irinotecan (Table IV). Each of four UGTIA genotypes [UGT1A1*6, UGTIA7 $(387 T>G), U G T 1 A 7(622 T>C)$ and $U G T 1 A 9 * 1 b]$ showed a significant association to irinotecan toxicity and linear trend $(\mathrm{p}<0.05)$. Similarly, two haplotypes (Hp-I and $H p-I I$ ) each showed a significant association to and linear trend with irinotecan toxicity $(\mathrm{p}<0.05)$. Among two patients received a starting dose of $100 \mathrm{mg} / \mathrm{m}^{2}$ irinotecan, diplotype of $H p-I V / V$ did not show toxicity and diplotype of $H p-V / V$ showed toxicity. Six patients excluded from FRUTIRI study did not show toxicity of irinotecan (a starting dose of $70 \mathrm{mg} / \mathrm{m}^{2}$; UGTIA diplotypes of $H p-I / V, I I / I V$ and $I I I / I V$ were found in 2, 3 and 1 patients). Regarding non-hematological toxicities, only 5 patients developed grade 3 diarrhea (UGTIA diplotype of these 5 patients consists of $4 H p-I / I I$ and $1 H p-I I / X I I)$.

Performances of the toxicity prediction system by genotype combination. To construct a system for predicting the risk of severe irinotecan toxicity, genetic data from 73 patients that constituted the training population were analyzed exhaustively; specifically, SFFS was used to assess gender, age and the individual genotypes at six polymorphic UGT1A sites (Fig. 2). In addition to the three possible genotypes (wild-type homozygous, heterozygous, variant homozygous), a fourth option for each site (designated 'unspecified genotype') was included into the algorithm. Similarly, patient gender (male, female, regardless of gender) and age ( $\leq 60,>60$ years old, regardless of age) were assessed. The cutoff value for age (60 years) was determined by Youden index obtained by the receiver operating characteristic (ROC) curve analysis with the training population. Among possible combinations $\left(4^{6} \times 3^{2}-1=36,863\right)$, the following cases were excluded: cases not found, single cases, and cases that represented positive or negative predictive values $<80 \%$. In order to optimize the combinations, 
Table III. Haplotype frequency.

\begin{tabular}{|c|c|c|c|c|c|c|c|c|}
\hline \multirow[b]{3}{*}{ Haplotypes } & \multicolumn{6}{|c|}{ UGT1A alleles } & \multirow{2}{*}{\multicolumn{2}{|c|}{ Allele frequencies }} \\
\hline & \multirow{2}{*}{$\begin{array}{c}\text { UGT1A9 } \\
* 1 b\end{array}$} & \multicolumn{2}{|c|}{ UGT1A7 } & \multicolumn{3}{|c|}{ UGTIAl } & & \\
\hline & & $387 \mathrm{~T}>\mathrm{G}$ & $622 \mathrm{~T}>\mathrm{C}$ & $* 60$ & $* 28$ & $* 6$ & $(\mathrm{n}=103)^{\mathrm{b}}$ & $(\mathrm{n}=123)^{\mathrm{c}}$ \\
\hline$H p-I$ & $\mathrm{~T}_{10}$ & $\mathrm{~T}$ & $\mathrm{~T}$ & $\mathrm{~T}$ & $\mathrm{TA}_{6}$ & $\mathrm{G}$ & 0.524 & 0.573 \\
\hline$H p-I I$ & $\mathrm{~T}_{9}^{\mathrm{a}}$ & $\mathrm{G}^{\mathrm{a}}$ & $\mathrm{C}^{\mathrm{a}}$ & $\mathrm{T}$ & $\mathrm{TA}_{6}$ & $\mathrm{~A}^{\mathrm{a}}$ & 0.170 & 0.159 \\
\hline$H p-I I I$ & $\mathrm{~T}_{9}{ }^{\mathrm{a}}$ & $\mathrm{G}^{\mathrm{a}}$ & $\mathrm{T}$ & $\mathrm{G}^{\mathrm{a}}$ & $\mathrm{TA}_{6}$ & $\mathrm{G}$ & 0.131 & 0.134 \\
\hline$H p-I V$ & $\mathrm{~T}_{9}^{\mathrm{a}}$ & $\mathrm{G}^{\mathrm{a}}$ & $\mathrm{C}^{\mathrm{a}}$ & $\mathrm{G}^{\mathrm{a}}$ & $\mathrm{TA}_{7}{ }^{\mathrm{a}}$ & $\mathrm{G}$ & 0.063 & 0.041 \\
\hline$H p-V$ & $\mathrm{~T}_{10}$ & $\mathrm{~T}$ & $\mathrm{~T}$ & $\mathrm{G}^{\mathrm{a}}$ & $\mathrm{TA}_{7}{ }^{\mathrm{a}}$ & $\mathrm{G}$ & 0.044 & 0.028 \\
\hline$H p-V I$ & $\mathrm{~T}_{9}^{\mathrm{a}}$ & $\mathrm{G}^{\mathrm{a}}$ & $\mathrm{C}^{\mathrm{a}}$ & $\mathrm{T}$ & $\mathrm{TA}_{6}$ & $\mathrm{G}$ & 0.015 & 0.016 \\
\hline$H p-V I I$ & $\mathrm{~T}_{9}^{\mathrm{a}}$ & $\mathrm{G}^{\mathrm{a}}$ & $\mathrm{C}^{\mathrm{a}}$ & $\mathrm{G}^{\mathrm{a}}$ & $\mathrm{TA}_{6}$ & $\mathrm{G}$ & 0.015 & 0.012 \\
\hline$H p-V I I I$ & $\mathrm{~T}_{9}{ }^{\mathrm{a}}$ & $\mathrm{G}^{\mathrm{a}}$ & $\mathrm{T}$ & $\mathrm{G}^{\mathrm{a}}$ & $\mathrm{TA}_{7}{ }^{\mathrm{a}}$ & $\mathrm{G}$ & 0.010 & 0.012 \\
\hline$H p-I X$ & $\mathrm{~T}_{10}$ & $\mathrm{~T}$ & $\mathrm{~T}$ & $\mathrm{G}^{\mathrm{a}}$ & $\mathrm{TA}_{6}$ & $\mathrm{G}$ & 0.010 & 0.008 \\
\hline$H p-X$ & $\mathrm{~T}_{10}$ & $\mathrm{G}^{\mathrm{a}}$ & $\mathrm{C}^{\mathrm{a}}$ & $\mathrm{T}$ & $\mathrm{TA}_{6}$ & $\mathrm{~A}^{\mathrm{a}}$ & 0.010 & 0.008 \\
\hline$H p-X I$ & $\mathrm{~T}_{9}{ }^{\mathrm{a}}$ & $\mathrm{G}^{\mathrm{a}}$ & $\mathrm{T}$ & $\mathrm{T}$ & $\mathrm{TA}_{6}$ & $\mathrm{G}$ & 0.005 & 0.004 \\
\hline$H p-X I I$ & $\mathrm{~T}_{10}$ & $\mathrm{~T}$ & $\mathrm{~T}$ & $\mathrm{~T}$ & $\mathrm{TA}_{6}$ & $\mathrm{~A}^{\mathrm{a}}$ & 0.005 & 0.004 \\
\hline
\end{tabular}

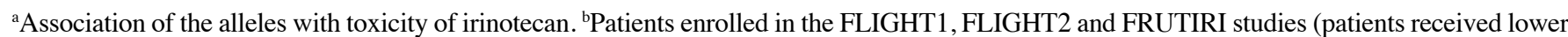
starting dose of irinotecan were not excluded). ${ }^{c}$ Patients subjected to the case-control study (patients received lower starting dose of irinotecan were excluded).

A Combinations for cases with toxicity (Positive)

\begin{tabular}{|c|c|c|c|c|c|c|c|c|c|c|}
\hline \multirow[b]{3}{*}{ Name } & \multicolumn{6}{|c|}{ UGT genotypes } & \multicolumn{2}{|c|}{ Clinical features } & \multirow{2}{*}{\multicolumn{2}{|c|}{ G3, G4/Total }} \\
\hline & $1 A 1^{*} 6$ & $1 A 1 * 28$ & $1 A 1^{*} 60$ & $1 A 7$ & $1 A 7$ & $1 A 9^{*} 1 b$ & Sex & Age & & \\
\hline & $211(G>A)$ & $(T A)_{6}>(T A)_{7}$ & $-3279(T>G)$ & $387(T>G)$ & $622(T>C)$ & $-118(T)_{9>10}$ & & & $n$ & (\%) \\
\hline P-I & ** & $\mathrm{TA}_{6} / \mathrm{TA} \mathrm{A}_{7}$ & ** & ** & ** & ** & Female & $>60$ & $4 / 4$ & (100.0) \\
\hline P-II & $\mathrm{G} / \mathrm{A}$ & ** & ** & ** & ** & $T_{9} / T_{10}$ & Male & $>60$ & $4 / 4$ & (100.0) \\
\hline P-III & A/A & ** & ** & ** & ** & ** & ** & ** & $2 / 2$ & (100.0) \\
\hline P-IV & ** & $\mathrm{TA}_{6} / \mathrm{TA}_{7}$ & ** & $G / G$ & $T / C$ & 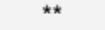 & 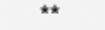 & ** & $2 / 2$ & (100.0) \\
\hline P-V & ** & $\mathrm{TA}_{6} / \mathrm{TA}_{6}$ & T/G & ** & $\mathrm{T} / \mathrm{C}$ & ** & ** & $>60$ & $2 / 2$ & (100.0) \\
\hline $\mathrm{P}-\mathrm{VI}$ & G/A & ** & ** & ** & ** & $\mathrm{T}_{9} / \mathrm{T}_{10}$ & ** & $>60$ & $9 / 10$ & $(90.0)$ \\
\hline P-VII & ** & ** & ** & ** & $\mathrm{T} / \mathrm{C}$ & ** & ** & $>60$ & $14 / 17$ & (82.4) \\
\hline P-VIII & ** & ** & ** & $\mathrm{G} / \mathrm{G}$ & $T / C$ & $T_{9} / T_{9}$ & ** & ** & $4 / 5$ & $(80.0)$ \\
\hline
\end{tabular}

B Combinations for cases without toxicity (Negative)

\begin{tabular}{|c|c|c|c|c|c|c|c|c|c|c|}
\hline \multirow[b]{3}{*}{ Name } & \multicolumn{6}{|c|}{ UGT genotypes } & \multicolumn{2}{|c|}{ Clinical features } & \multirow{2}{*}{\multicolumn{2}{|c|}{ G0-G2/Total }} \\
\hline & $1 A 1^{\star} 6$ & $1 A 1^{*} 28$ & $1 A 1^{*} 60$ & $1 A 7$ & $1 A 7$ & $1 A 9^{*} 1 b$ & Sex & Age & & \\
\hline & $211(G>A)$ & $(\mathrm{TA})_{6}>(\mathrm{TA})_{7}$ & $-3279(T>G)$ & $387(T>G)$ & $622(\mathrm{~T}>\mathrm{C})$ & $-118(T)_{9>10}$ & & & $n$ & $(\%)$ \\
\hline $\mathrm{N}-\mathrm{I}$ & $* \star$ & $* *$ & $* *$ & $T / T$ & $* *$ & $* *$ & Male & $\leqq 60$ & $6 / 6$ & $(100.0)$ \\
\hline $\mathrm{N}-\mathrm{II}$ & G/G & $\mathrm{TA}_{6} / \mathrm{TA}_{7}$ & ** & $\star \star *$ & $\star *$ & $* *$ & $\star \star *$ & $\leqq 60$ & $5 / 5$ & $(100.0)$ \\
\hline $\mathrm{N}-\mathrm{III}$ & G/G & $\mathrm{TA}_{6} / \mathrm{TA}_{6}$ & T/G & $* *$ & $* *$ & $* *$ & Female & $* *$ & $3 / 3$ & $(100.0)$ \\
\hline $\mathrm{N}-\mathrm{IV}$ & G/G & $\mathrm{TA}_{6} / \mathrm{TA}_{7}$ & $T / G$ & $* \star$ & $* \star$ & ** & Male & ** & $3 / 3$ & $(100.0)$ \\
\hline $\mathrm{N}-\mathrm{V}$ & G/G & $* *$ & $\mathrm{~T} / \mathrm{T}$ & T/G & $\star \star$ & ** & $* *$ & ** & $2 / 2$ & (100.0) \\
\hline $\mathrm{N}-\mathrm{VI}$ & G/A & $* *$ & ** & $\star \star$ & $\mathrm{C} / \mathrm{C}$ & $* *$ & $\star *$ & ** & $2 / 2$ & $(100.0)$ \\
\hline $\mathrm{N}-\mathrm{VII}$ & $\mathrm{G} / \mathrm{G}$ & $* \star$ & $\mathrm{T} / \mathrm{T}$ & $* *$ & $* *$ & $\star *$ & Male & $* *$ & $12 / 15$ & $(80.0)$ \\
\hline N-VIII & $\star *$ & $\star *$ & $\mathrm{~T} / \mathrm{T}$ & $\star \star$ & ** & $\mathrm{T}_{10} / \mathrm{T}_{10}$ & Male & $* *$ & $12 / 15$ & (80.0) \\
\hline $\mathrm{N}-\mathrm{IX}$ & $\star \star *$ & $\star *$ & $\mathrm{~T} / \mathrm{T}$ & $\star \star$ & $\star *$ & $* \star$ & $\star \star$ & $\leqq 60$ & $12 / 15$ & $(80.0)$ \\
\hline $\mathrm{N}-\mathrm{X}$ & $\mathrm{G} / \mathrm{G}$ & $\mathrm{TA}_{6} / \mathrm{TA}_{6}$ & $\star \star$ & $\star \star *$ & $\star \star$ & $\star \star *$ & Female & $* *$ & $8 / 10$ & $(80.0)$ \\
\hline
\end{tabular}

Figure 2. The UGT1A genotype combinations that predict the presence or absence of severe irinotecan toxicity based on statistical pattern recognition. (A) A total of 8 combinations (P-I to P-VIII) for positive prediction of the toxicity and (B) 10 combinations (N-I to N-X) for negative prediction are presented. (A) The 8 combinations (P-I to P-VIII) that predict the presence of irinotecan toxicity are shown. (B) The 10 combinations (N-I to N-X) that predict the absence of irinotecan toxicity are shown. Eight factors-patient age, patient gender and genotypes at six $U G T 1 A$ sites $[U G T 1 A 1 * 6, * 28, * 60,1 A 7(387 T>G)$, $1 A 7(622 T>C)$ and $1 A 9 * 1 b]$ were used with sequential floating forward selection (SFFS) for statistical pattern recognition as described in Materials and methods. Homozygosity for alleles associated with irinotecan toxicity, heterozygosity and homozygosity for alleles not associated with irinotecan toxicity are indicated by red, blue and green cells, respectively. ${ }^{* *}$ The un-specified categories (regardless of genotypes, gender or age). 
Table IV. Associations between UGT1A genotypes/haplotypes and irinotecan toxicity.

\begin{tabular}{|c|c|c|c|c|c|c|}
\hline & & \multicolumn{3}{|c|}{ Toxicity } & \multicolumn{2}{|c|}{$\mathrm{p}$-value } \\
\hline & & Yes & No & (\% of yes) & Fisher's exact & $\mathrm{CA}$ trend \\
\hline \multicolumn{7}{|l|}{ Genotypes } \\
\hline \multirow{3}{*}{ UGTIA1*6 } & $-/-$ & 27 & 57 & (32.1) & 0.002 & 0.001 \\
\hline & $-/ * 6$ & 21 & 15 & $(58.3)$ & & \\
\hline & $* 6 / * 6$ & 3 & 0 & $(100.0)$ & & \\
\hline \multirow[t]{3}{*}{$U G T 1 A 1 * 28$} & $-/-$ & 40 & 63 & $(38.8)$ & 0.218 & - \\
\hline & $-/ 1 * 28$ & 11 & 9 & $(55.0)$ & & \\
\hline & $1 * 28 / 1 * 28$ & - & - & - & & \\
\hline \multirow[t]{3}{*}{$U G T 1 A 1 * 60$} & $-/-$ & 27 & 44 & $(38.0)$ & 0.349 & 0.219 \\
\hline & $-/ 1 * 60$ & 20 & 26 & $(43.5)$ & & \\
\hline & $1 * 60 / 1 * 60$ & 4 & 2 & $(66.7)$ & & \\
\hline \multirow{3}{*}{$\begin{array}{l}U G T 1 A 7 \\
\quad(387 \mathrm{~T}>\mathrm{G})\end{array}$} & $387 \mathrm{~T} / \mathrm{T}$ & 9 & 32 & $(22.0)$ & 0.005 & 0.002 \\
\hline & $387 \mathrm{~T} / \mathrm{G}$ & 34 & 35 & (49.3) & & \\
\hline & $387 \mathrm{G} / \mathrm{G}$ & 8 & 5 & (61.5) & & \\
\hline \multirow{3}{*}{$\begin{array}{l}U G T 1 A 7 \\
(622 \mathrm{~T}>\mathrm{C})\end{array}$} & $622 \mathrm{~T} / \mathrm{T}$ & 18 & 52 & $(25.7)$ & $<0.001$ & $<0.001$ \\
\hline & $622 \mathrm{~T} / \mathrm{C}$ & 31 & 17 & (64.6) & & \\
\hline & $622 \mathrm{C} / \mathrm{C}$ & 2 & 3 & $(40.0)$ & & \\
\hline \multirow[t]{3}{*}{$U G T 1 A 9 * 1 b$} & $9 * 1 b / 9 * 1 b$ & 9 & 34 & $(20.9)$ & 0.003 & 0.001 \\
\hline & $-/ 9 * 1 b$ & 34 & 33 & $(50.7)$ & & \\
\hline & $-/-$ & 8 & 5 & $(61.5)$ & & \\
\hline \multicolumn{7}{|l|}{ Haplotypes } \\
\hline \multirow[t]{3}{*}{$H p-I$} & $0^{\mathrm{a}}$ & 12 & 6 & $(66.7)$ & 0.002 & $<0.001$ \\
\hline & $1^{\mathrm{a}}$ & 32 & 37 & $(46.4)$ & & \\
\hline & $2^{\mathrm{a}}$ & 7 & 29 & $(19.4)$ & & \\
\hline \multirow[t]{3}{*}{$H p-I I$} & $0^{\mathrm{a}}$ & 27 & 59 & $(31.4)$ & 0.001 & $<0.001$ \\
\hline & $1^{\mathrm{a}}$ & 22 & 13 & $(62.9)$ & & \\
\hline & $2^{\mathrm{a}}$ & 2 & 0 & (100.0) & & \\
\hline \multirow[t]{3}{*}{$H p-I I I$} & $0^{\mathrm{a}}$ & 38 & 53 & $(41.8)$ & 0.517 & 0.900 \\
\hline & $1^{\mathrm{a}}$ & 12 & 19 & $(38.7)$ & & \\
\hline & $2^{\mathrm{a}}$ & 1 & 0 & $(100.0)$ & & \\
\hline \multicolumn{7}{|c|}{ Clinical features } \\
\hline \multirow[t]{2}{*}{ Gender } & Male & 31 & 47 & (39.7) & 0.705 & - \\
\hline & Female & 20 & 25 & $(44.4)$ & & \\
\hline \multirow[t]{2}{*}{ Age } & $\leq 60$ & 15 & 35 & $(30.0)$ & 0.027 & - \\
\hline & $>60$ & 36 & 37 & (49.3) & & \\
\hline
\end{tabular}

${ }^{a}$ Number of alleles carried by the patient. CA, Cochran-Armitage trend test.

categorization according to predictive value and exclusion of redundant combinations in each category were performed. As a result, 8 combinations (P-I to P-VIII, Fig. 1A) appeared to predict an increased risk of toxicity, and 10 combinations (N-I to N-X, Fig. 1B) appeared to predict a lack of toxicity.

The system for predicting irinotecan toxicity based on combinations of 8 factors (6 genotypes, gender and age) was generated using data from of all 73 patients in the training population. The system was then applied to data from 84.9 and $86.0 \%$ of the patients in the training and validation populations, respectively (Table V). This prediction system showed $83.9 \%$ accuracy (positive predictive value, $86.4 \%$; negative predictive value, $82.5 \%)$ for the training population $(n=62)$ and $72.1 \%$ accuracy (positive predictive value, $70.0 \%$; negative predictive value, $72.7 \%)$ for the validation population $(n=43)$. When patients who were not applied to the combinations were included, the performance of the system was $71.2 \%$ accuracy (sensitivity, $55.9 \%$; specificity, $84.6 \%$ ) in training population $(n=73)$ and $62.0 \%$ accuracy (sensitivity, $41.2 \%$; specificity, $72.7 \%$ ) in validation population $(n=50)$. Odds ratios of positive prediction for irinotecan toxicity for this prediction system were 8.0 (95\% CI, 1.5-42.5) and 16.3 (95\% CI, 2.2-121.4) in training and validation populations, respectively $(\mathrm{p}<0.05$, Table VI).

Patients with either of three $U G T 1 A$ alleles [UGT1A1*6, UGT1A7 $(622 T>C)$ or UGT1A9*1b], UGT1A haplotype-I or haplotype-II showed significant association to severe irinotecan toxicity $(\mathrm{p}<0.05)$ in both the training and validation populations (data not shown). 
Table V. Predicitive performance for irinotecan toxicity by the genotype combinations.

\begin{tabular}{|c|c|c|c|c|}
\hline & \multicolumn{2}{|c|}{ Training $(n=73)$} & \multicolumn{2}{|c|}{ Validation $(n=50)$} \\
\hline & $\mathrm{n}$ & $(\%)$ & $\mathrm{n}$ & $(\%)$ \\
\hline Matched with the combination ${ }^{a}$ & $62 / 73$ & $(84.9)$ & $43 / 50$ & $(86.0)$ \\
\hline Accuracy in applied patients & $52 / 62$ & $(83.9)$ & $31 / 43$ & $(72.1)$ \\
\hline Positive predictive value ${ }^{\mathrm{b}}$ & $19 / 22$ & $(86.4)$ & $7 / 10$ & $(70.0)$ \\
\hline Negative predictive value ${ }^{b}$ & $33 / 40$ & $(82.5)$ & $24 / 33$ & $(72.7)$ \\
\hline Accuracy & $52 / 73$ & $(71.2)$ & $31 / 50$ & $(62.0)$ \\
\hline Sensitivity & $19 / 34$ & $(55.9)$ & $7 / 17$ & $(41.2)$ \\
\hline Specificity & $33 / 39$ & $(84.6)$ & $24 / 33$ & $(72.7)$ \\
\hline
\end{tabular}

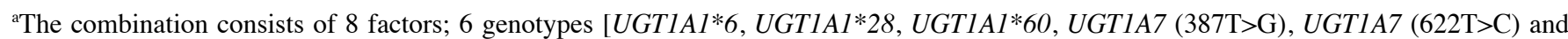

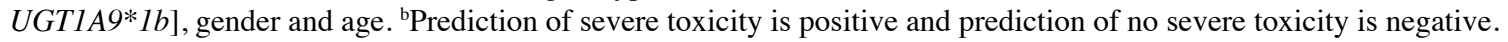

\section{Discussion}

The novel system for predicting severe irinotecan toxicity described here was based on genotypes at 6 polymorphic sites in UGT1A and 2 basic clinical features; notably, it showed high predictive performance even though the treatment regimens differed among the training and validation patients (Tables $\mathrm{V}$ and VI). The odds ratio of positive prediction for severe irinotecan toxicity was higher for this prediction system than for that of any other haplotype or for that of any genotype (Table VI). The performance of this prediction system was reduced from the $83.9 \%$ accuracy seen with applied patients to this system in the training population to $72.1 \%$ accuracy in the validation. With regard to positive prediction, the inconsistency in accuracy between training and validation populations was seen when the combinations included the $U G T 1 A 9 * 1 b$ site and patient age (P-II, VI and VII in Fig. 2). The frequencies of UGT1A9*1b genotype differed between the training and validation populations; moreover, the UGT1A9*1b alleles were not in Hardy-Weinberg equilibrium in the validation population (data not shown). The cutoff value for patient age (60 years old) was determined by a ROC curve generated with data from the training population; however, previous studies used a cutoff age of 65 years $(20,21)$. Indeed, one patient without toxicity, but predicted as presence of toxicity in this system, was aged 63 years.

Some genotypic combinations decreased the performance of negative prediction for sever irinotecan toxicity in the validation population relative to the training population (N-II, IV, and V in Fig. 2). Specifically, 36.4\% $(n=4 / 11)$ of patients in training population with a combined genotype that included heterozygous for $U G T 1 A 1 * 28$ alleles and $U G T 1 A 1 * 6(-/-)$ experienced severe irinotecan toxicity, but $66.7 \%(n=4 / 6)$ of the patients in validation population with the same genotype combinations (UGT1A1*6, -/- and UGT1A1*28, -/+) showed severe toxicity. Of the 73 patients in the training population and the 50 in the validation population, $11(15.1 \%)$ and $7(14.0 \%)$, respectively, were matched with neither of the combination in our prediction system. Interestingly, the incidence of severe toxicity among patients who were not matched with either combination identified by this prediction system was $72.7 \%$ (training population) and $14.3 \%$ (validation population) (Table VI). Therefore, the frequency of the irinotecan toxicity among patients who do not have any combination of UGT1A variants identified by this novel prediction system might be due to factors other than UGT1A polymorphisms.

Many published studies have focused on associations between irinotecan toxicity, irinotecan efficacy, or both and any one or more of each UGT1A variants examined here (10-19,31,32). Patients, especially Asian patients, homozygous for $U G T 1 A 1 * 6$ or $* 28$ or compound heterozygous for these variants are at high risk for hematologic toxicity $(13,33,34)$. In this study, each patient homozygous for $U G T 1 A l^{*} 6(\mathrm{n}=3)$ and those compound heterozygous for UGTIAl*6 and *28 (n=3) showed severe hematologic toxicity; however, 45 patients of the remaining 117 patients still exhibited severe irinotecan toxicity. UGT1A $1 * 6$ and $* 28$ each have strong effects on UGT1A1 activity and expression, but frequency of each allele is low; moreover, the frequencies of each allele differ between races $(11,14,35-37)$. Among the patients that lacked these rare, highly effective variants, this novel prediction system could accurately predict whether there is severe irinotecan toxicity.

Here, as in previous studies, each identified UGT1A haplotypes was useful for precisely predicting the presence or absence of severe irinotecan toxicity (14,18,38-40). Consistent with our study, Cecchin et al reported that a haplotype comprising UGT1AI*28 (-), UGT1A1*60 (-), UGT1A7 (387T and $622 T)$, and $U G T 1 A 9 * 1 b(+)$ was a predictor of severe hematologic toxicity during the entire course of therapy (18). However, determining the haplotypes for any one patient is a difficult clinical measurement. Therefore, the genotypes at each of the 6 sites (rather than the haplotype or diplotype) could be used for clinical assessments.

Our prediction system depend not only on UGT1A genotypes but also on patient gender and age. Previous studies showed that patient gender and age were related to the risk of irinotecan toxicity (20-22). In the training population, patient age was associated with severe irinotecan toxicity, but patient gender was not (Table IV). Interestingly, when patient age, patient gender or both the patient age and gender were excluded from the factors used by the prediction system, the 


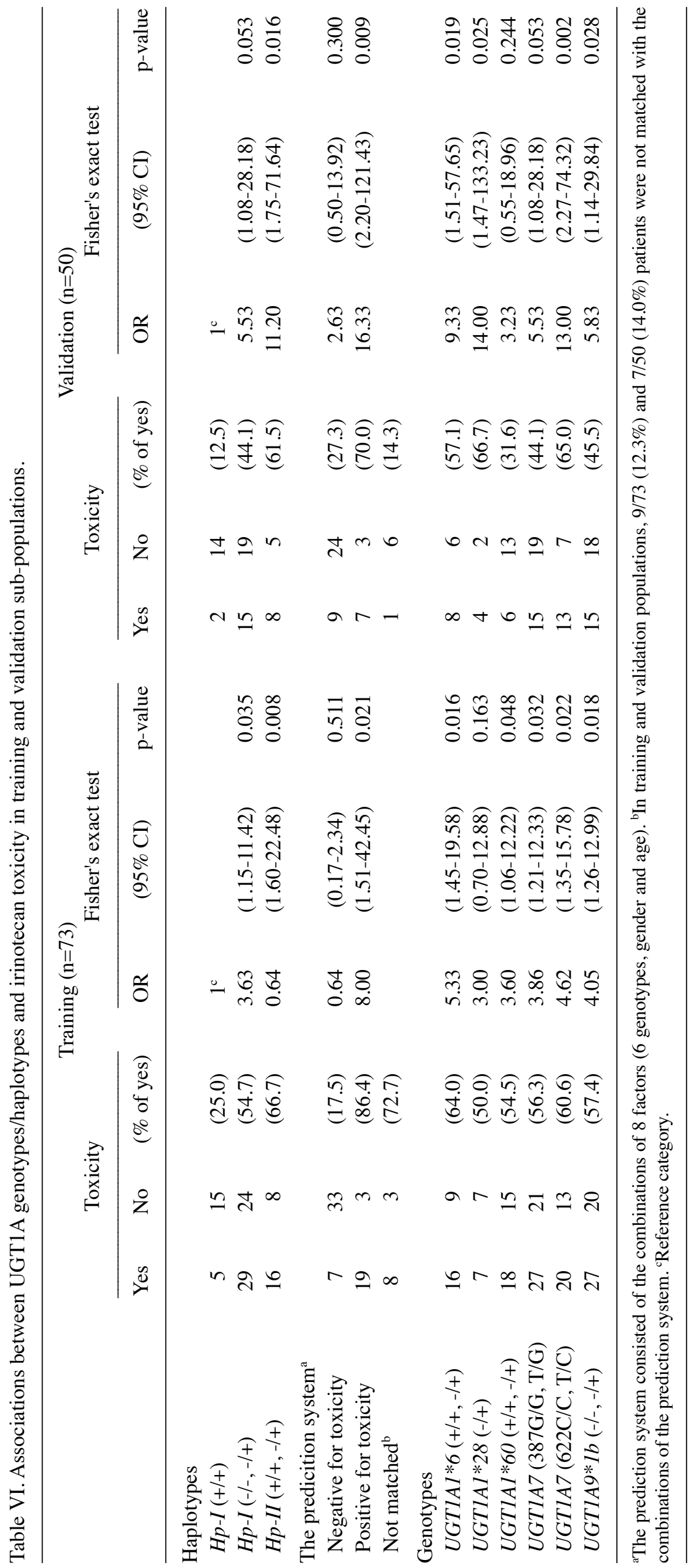


number of patients that matched with the prediction system decreased, although the system maintained the high positive and negative predictive values (data not shown).

The SFFS algorithm could be modified to include other factors (e.g., mutations in the tumor, patients' clinical characteristics, additional genetic variants, etc.) to improve the prediction performance. Such modifications may result in a system that could meaningfully predict clinical outcomes, including tumor response. Recent advances in technology for sequencing whole genomes of individuals may lead to substantial increases in information that might be useful for personalized therapy. However, such complicated information could not be efficiently or fully utilized in the currently available formats. SFFS could easily construct a system that can utilize huge data sets such as whole-genome sequences. Our strategy for developing SFFSbased systems for clinical use could serve as a powerful tool for advancing personalized therapy, although additional prospective study of this prediction system is needed.

\section{Acknowledgements}

This study was supported in part by a non-profit organization Epidemiological and Clinical Research Information Network (ECRIN) and by a Grant-in-Aid for Scientific Research from the Ministry of Education, Culture, Sports, Science and Technology of Japan (JSPS KAKENHI grant nos. 21591725 and 19591545). We thank Ms. Mai Hatta for clinical research coordination.

\section{References}

1. Douillard JY, Cunningham D, Roth AD, Navarro M, James RD, Karasek P, Jandik P, Iveson T, Carmichael J, Alak1 M, Gruia G Awad L and Rougier P: Irinotecan combined with fluorouracil compared with fluorouracil alone as first-line treatment for metastatic colorectal cancer: a multicentre randomised trial. Lancet 355: 1041-1047, 2000.

2. Saltz LB, Cox JV, Blanke C, Rosen LS, Fehrenbacher L, Moore MJ, Maroun JA, Ackland SP, Locker PK, Pirotta N, Elfring GL and Miller LL: Irinotecan plus fluorouracil and leucovorin for metastatic colorectal cancer. Irinotecan Study Group. N Engl J Med 343: 905-914, 2000.

3. Tournigand C, André T, Achille E, Lledo G, Flesh M, Mery-Mignard D, Quinaux E, Couteau C, Buyse M, Ganem G, Landi B, Colin P, Louvet $\mathrm{C}$ and de Gramont A: FOLFIRI followed by FOLFOX6 or the reverse sequence in advanced colorectal cancer: a randomized GERCOR study. J Clin Oncol 22: 229-237, 2004

4. Hazama S, Nagashima A, Kondo H, Yoshida S, Shimizu R, Araki A, Yoshino S, Okayama N, Hinoda Y and Oka M: Phase I study of irinotecan and doxifluridine for metastatic colorectal cancer focusing on the UGT1A1*28 polymorphism. Cancer Sci 101: 722-727, 2010.

5. Hazama S, Mishima H, Tsunedomi R, Okuyama Y, Kato T, Takahashi K, Nozawa H, Ando H, Kobayashi M, Takemoto H, Nagata N, Kanekiyo S, Inoue Y, Hamamoto Y, Fujita Y, Hinoda Y, Okayama N, Oba K, Sakamoto J and Oka M $\mathrm{UGT} 1 \mathrm{~A} 1 * 6,1 \mathrm{~A} 7 * 3$, and $1 \mathrm{~A} 9 * 22$ genotypes predict severe neutropenia in FOLFIRI-treated mCRC in two prospective studies in Japan. Cancer Sci 104: 1662-1669, 2013.

6. Kanekiyo S, Hazama S, Kondo H,Nagashima A, Eto R, Yoshida S, Shimizu R, Araki A, Yamamoto T, Uchiyama T, Yoshino S, Okayama N, Hinoda Y and Oka M: UDP-glucuronosyltransferase (UGT) $1 \mathrm{~A} 1 * 28$ polymorphism-directed phase II study of irinotecan with 5'-deoxy-5-fluorouridine (5'-DFUR) for metastatic colorectal cancer. Anticancer Res 33: 3423-3430, 2013.

7. Kawato Y, Aonuma M, Hirota Y, Kuga $\mathrm{H}$ and Sato K: Intracellular roles of SN-38, a metabolite of the camptothecin derivative CPT-11, in the antitumor effect of CPT-11. Cancer Res 51: 4187-4191, 1991.
8. Rivory LP, Bowles MR, Robert J and Pond SM: Conversion of irinotecan (CPT-11) to its active metabolite, 7-ethyl-10-hydroxycamptothecin (SN-38), by human liver carboxylesterase. Biochem Pharmacol 52: 1103-1111, 1996.

9. Mathijssen RH, van Alphen RJ, Verweij J, Loos WJ, Nooter K, Stoter G and Sparreboom A: Clinical pharmacokinetics and metabolism of irinotecan (CPT-11). Clin Cancer Res 7: 2182-2194, 2001

10. Iyer L, Das S, Janisch L, Wen M, Ramírez J, Karrison T, Fleming GF, Vokes EE, Schilsky RL and Ratain MJ: UGT1A $1 * 28$ polymorphism as a determinant of irinotecan disposition and toxicity. Pharmacogenomics J 2: 43-47, 2002.

11. Toffoli G, Cecchin E, Corona G, Russo A, Buonadonna A, D'Andrea M, Pasetto LM, Pessa S, Errante D, De Pangher V, Giusto M, Medici M, Gaion F, Sandri P, Galligioni E, Bonura S, Boccalon M, Biason P and Frustaci S: The role of UGT1A1*28 polymorphism in the pharmacodynamics and pharmacokinetics of irinotecan in patients with metastatic colorectal cancer. J Clin Oncol 24: 3061-3068, 2006.

12. Guillemette C, Ritter JK, Auyeung DJ, Kessler FK and Housman DE: Structural heterogeneity at the UDP-glucuronosyltransferase 1 locus: functional consequences of three novel missense mutations in the human UGT1A7 gene. Pharmacogenetics 10: 629-644, 2000.

13. Ando Y, Saka H, Ando M, Sawa T, Muro K, Ueoka H, Yokoyama A, Saitoh S, Shimokata K and Hasegawa Y: Polymorphisms of UDP-glucuronosyltransferase gene and irinotecan toxicity: a pharmacogenetic analysis. Cancer Res 60: 6921-6926, 2000.

14. Ando M, Ando Y, Sekido Y, Ando M, Shimokata K and Hasegawa Y: Genetic polymorphisms of the UDP-glucuronosyltransferase 1A7 gene and irinotecan toxicity in Japanese cancer patients. Jpn J Cancer Res 93: 591-597, 2002.

15. Yamanaka H, Nakajima M, Katoh M, Hara Y, Tachibana O, Yamashita J, McLeod HL and Yokoi T: A novel polymorphism in the promoter region of human UGT1A9 gene (UGT1A9*22) and its effects on the transcriptional activity. Pharmacogenetics 14: 329-332, 2004

16. Sai K, Saeki M, Saito Y, Ozawa S, Katori N, Jinno H, Hasegawa R, Kaniwa N, Sawada J, Komamura K, Ueno K, Kamakura S, Kitakaze M, Kitamura Y, Kamatani N, Minami H, Ohtsu A, Shirao K, Yoshida T and Saijo N: UGT1A1 haplotypes associated with reduced glucuronidation and increased serum bilirubin in irinotecan-administered Japanese patients with cancer. Clin Pharmacol Ther 75: 501-515, 2004.

17. Han JY, Lim HS, Shin ES, Yoo YK, Park YH, Lee JE, Jang IJ, Lee DH and Lee JS: Comprehensive analysis of UGT1A polymorphisms predictive for pharmacokinetics and treatment outcome in patients with non-small-cell lung cancer treated with irinotecan and cisplatin. J Clin Oncol 24: 2237-2244, 2006.

18. Cecchin E, Innocenti F, D'Andrea M, Corona G, De Mattia E, Biason P, Buonadonna A and Toffoli G: Predictive role of the UGT1A1, UGT1A7, and UGT1A9 genetic variants and their haplotypes on the outcome of metastatic colorectal cancer patients treated with fluorouracil, leucovorin, and irinotecan. J Clin Oncol 27: 2457-2465, 2009.

19. Fujita K, Ando Y, Nagashima F, Yamamoto W, Eodo H, Araki K, Kodama K, Miya T, Narabayashi M and Sasaki Y: Genetic linkage of UGT1A7 and UGT1A9 polymorphisms to UGT1A $1 * 6$ is associated with reduced activity for SN-38 in Japanese patients with cancer. Cancer Chemother Pharmacol 60: 515-522, 2007.

20. Roth AD, Yan P, Dietrich D, Fiocca R, Bodoky G, Labianca R, Cunningham D, Van Cutsem E, Bosman F and Tejpar S: Is UGT1A $1 * 28$ homozygosity the strongest predictor for severe hematotoxicity in patients treated with 5-fluorouracil (5-FU)-irinotecan (IRI)? Results of the PETACC 3 - EORTC 40993 - SAKK 60/00 trial comparing IRI/5-FU/folinic acid (FA) to 5-FU/FA in stage II-III colon cancer (COC) patients. J Clin Oncol 26 (Suppl): abs 4036, 2008.

21. Kweekel D, Guchelaar HJ and Gelderblom H: Clinical and pharmacogenetic factors associated with irinotecan toxicity. Cancer Treat Rev 34: 656-669, 2008.

22. Innocenti F, Kroetz DL, Schuetz E, Dolan ME, Ramírez J, Relling M, Chen P, Das S, Rosner GL and Ratain MJ: Comprehensive pharmacogenetic analysis of irinotecan neutropenia and pharmacokinetics. J Clin Oncol 27: 2604-2614, 2009. 
23. UGT Alleles Nomenclature Home Page. UGT Nomenclature Committee. June 2005. http://www.pharmacogenomics.pha. ulaval.ca/cms/site/pharmacogenomics/ugt_alleles. Accessed 04.01.2013.

24. Pudil P, Novovicova J and Kittler J: Floating search methods in feature selection. Pattern Recognition Lett 15: 1119-1125, 1994.

25. Okuyama Y, Hazama S, Nozawa H, Kobayashi M, Takahashi K, Fujikawa K, Kato T, Nagata N, Kimura H, Oba K, Sakamoto J and Mishima H: Prospective phase II study of FOLFIRI for mCRC in Japan, including the analysis of UGT1A1 28/6 polymorphisms. Jpn J Clin Oncol 41: 477-482, 2011.

26. Hirata K, Nagata N, Kato T, Okuyama Y, Andoh H, Takahashi K, Oba K, Sakamoto J, Hazama S and Mishima H: Prospective phase II trial of second-line FOLFIRI in patients with advanced colorectal cancer including analysis of UGT1A1 polymorphisms: FLIGHT 2 study. Anticancer Res 34: 195-201, 2014.

27. Wang L, Hirayasu K, Ishizawa M and Kobayashi Y: Purification of genomic DNA from human whole blood by isopropanol-fractionation with concentrated NaI and SDS. Nucleic Acids Res 22: $1774-1775,1994$.

28. Okayama N, Hamanaka Y, Suehiro Y, Hasui Y, Nakamura J and Hinoda Y: Association of interleukin-10 promoter single nucleotide polymorphisms-819 T/C and $-592 \mathrm{~A} / \mathrm{C}$ with aging. J Gerontol A Biol Sci Med Sci 60: 1525-1529, 2005.

29. Barrett JC, Fry B, Maller J and Daly MJ: Haploview: analysis and visualization of LD and haplotype maps. Bioinformatics 21: $263-265,2005$.

30. The R project website, http://www.r-project.org/.

31. Smith NF, Figg WD and Sparreboom A: Pharmacogenetics of irinotecan metabolism and transport: an update. Toxicol In Vitro 20: 163-175, 2006.

32. Lamas MJ, Duran G, Balboa E, Bernardez B, Candamio S, Vidal Y, Mosquera A, Giraldez JM, Lopez R, Carracedo A and Barros F: The value of genetic polymorphisms to predict toxicity in metastatic colorectal patients with irinotecanbased regimens. Cancer Chemother Pharmacol 69: 1591-1599, 2012.

33. Araki K, Fujita K, Ando Y, Nagashima F, Yamamoto W, Endo H, Miya T, Kodama K, Narabayashi M and Sasaki Y: Pharmacogenetic impact of polymorphisms in the coding region of the UGT1A1 gene on SN-38 glucuronidation in Japanese patients with cancer. Cancer Sci 97: 1255-1259, 2006.
34. Satoh T, Ura T, Yamada Y, Yamazaki K, Tsujinaka T, Munakata M, Nishina T, Okamura S, Esaki T, Sasaki Y, Koizumi W, Kakeji Y, Ishizuka N, Hyodo I and Sakata Y: Genotype-directed, dose-finding study of irinotecan in cancer patients with UGT1A $1 * 28$ and/or UGT1A $1 * 6$ polymorphisms. Cancer Sci 102: 1868-1873, 2011.

35. Innocenti F, Undevia SD, Iyer L, Chen PX, Das S, Kocherginsky M, Karrison T, Janisch L, Ramírez J, Rudin CM, Vokes EE and Ratain MJ: Genetic variants in the UDP-glucuronosyltransferase $1 \mathrm{~A} 1$ gene predict the risk of severe neutropenia of irinotecan. J Clin Oncol 22: 1382-1388, 2004.

36. Innocenti F, Liu W, Chen P, Desai AA, Das S and Ratain MJ: Haplotypes of variants in the UDP-glucuronosyltransferase1A9 and 1A1 genes. Pharmacogenet Genomics 15: 295-301, 2005.

37. Massacesi C, Terrazzino S, Marcucci F, Rocchi MB, Lippe P, Bisonni R, Lombardo M, Pilone A, Mattioli R and Leon A: Uridine diphosphate glucuronosyl transferase 1A1 promoter polymorphism predicts the risk of gastrointestinal toxicity and fatigue induced by irinotecan-based chemotherapy. Cancer 106: 1007-1016, 2006.

38. Minami H, Sai K, Saeki M, Saito Y, Ozawa S, Suzuki K, Kaniwa N, Sawada J, Hamaguchi T, Yamamoto N, Shirao K, Yamada Y, Ohmatsu H, Kubota K, Yoshida T, Ohtsu A and Saijo N: Irinotecan pharmacokinetics/pharmacodynamics and UGT1A genetic polymorphisms in Japanese: roles of UGT1A $1 * 6$ and *28. Pharmacogenet Genomics 17: 497-504, 2007.

39. Saito Y, Sai K, Maekawa K, Kaniwa N, Shirao K, Hamaguchi T, Yamamoto N, Kunitoh H, Ohe Y, Yamada Y, Tamura T, Yoshida T, Minami H, Ohtsu A, Matsumura Y, Saijo N and Sawada J: Close association of UGT1A9 IVS1+399C $>$ T with UGT1A $1 * 28, * 6$, or $* 60$ haplotype and its apparent influence on 7-ethyl-10-hydroxycamptothecin (SN-38) glucuronidation in Japanese. Drug Metab Dispos 37: 272-276, 2009.

40. Martinez-Balibrea E, Abad A, Martínez-Cardús A, Ginés A, Valladares M, Navarro M, Aranda E, Marcuello E, Benavides M, Massutí B, Carrato A, Layos L, Manzano JL and Moreno V: UGT1A and TYMS genetic variants predict toxicity and response of colorectal cancer patients treated with first-line irinotecan and fluorouracil combination therapy. Br J Cancer 103: 581-589, 2010. 